\title{
PLANEJAMENTO E GESTÃO TERRITORIAL UM CAMINHO PARA A SUSTENTABILIDADE RURAL
}

\section{PLANNING AND TERRITORIAL MANAGEMENT PATHWAY TO RURAL SUSTAINABILITY}

\section{Luana Fração}

Acadêmica do curso de Geografia. Unesc. E-mail: fracaoluana@gmail.com

Bárbara Janaína Moraes de Oliveira

Acadêmica do Curso de Engenharia de Agrimensura. Unesc. E-mail: barbara.moraes123@hotm ail.com

Nilzo Ivo Ladwig

Professor do Programa de Pós-Graduação em Ciências Ambientais. UNESC. E-mail: ladwig@unesc.net

\section{RESUMO}

Ações de planejamento e gestão territorial de espaços rurais é uma forma de administrar a produção agrícola no caminho da sustentabilidade, minimizando os impactos negativos e maximizando os impactos positivos decorrentes do processo produtivo. $\mathrm{O}$ artigo é parte de um projeto de extensão que tem como objeto de estudo o território da Associação de Drenagem e Irrigação Santo Isidoro e como objetivo estruturar e analisar resultados de uma base de dados econômicos, sociais e ambientais coletados em campo e armazenados em ambiente de sistema de informação geográfica. A análise destes dados auxiliou para traçar inicialmente um diagnóstico do processo produtivo que poderá auxiliar no planejamento e na gestão territorial da área que compreende as propriedades dos associados, considerando as problemáticas de competitividade e os gastos com insumos no cultivo do arroz, incorporando neste contexto os atributos relacionados a sustentabilidade. Os resultados nesta etapa do projeto se mostraram eficientes e que darão possibilidade de condução de ações de planejamento e gestão por parte da diretoria com vistas à sustentabilidade da atividade que é uma exigência.

Palavras chave: Território; Espaço rural; Associativismo

\section{ABSTRACT}

Planning and territorial management actions for rural areas is a way to manage agricultural production with sustainability, minimizing negative impacts and maximizing positive impacts resulting from the production process. The article is part of an extension project that has the object of studying the territory of the Santo Isidoro Association and aims to structure and analyze results from an economic, social and environmental database collected in the field and stored in a geographic information system environment. The analysis of these data helped to initially trace a diagnosis of the production process that may assist in the planning and territorial management of the area that comprises the members' properties, considering the competitiveness issues and the expenses with inputs in rice cultivation, incorporating the related attributes sustainability. The results at this stage of the project proved to be efficient and will give the possibility of conducting planning and management actions by the board with a view to the sustainability of the activity, which is a requirement.

Keywords: Territory; Rural space; Associations 


\section{INTRODUÇÃO}

Desde a década de 1980, inúmeros autores vêm discutindo sobre a definição de planejamento e gestão territorial. Considerando as várias abordagens bibliográficas existentes, pode-se definir como o fator de controle da organização social comandado por tomada de decisões em um grupo de classe. (Corrêa, 1992; Becker, 2012; Dallabrida, 2015b). Em uma sociedade meramente capitalista, os agentes econômicos e governamentais definem condições distintas de produção, garantindo territórios de diferenciação em um determinado local. Esta diferenciação implica no desenvolvimento de atividades empreendedoras e inovadoras cujo objetivo é o desenvolvimento regional. Neste artigo será priorizado o desenvolvimento do espaço rural.

O desenvolvimento territorial em ambiente rural constitui-se em propostas concretas de um espaço portador de identidade própria, estabelecendo ligações de desenvolvimento sustentável e capaz de representar todo o potencial de suas estruturas socioeconômicas (ORTEGA, 2007). No que diz respeito a sustentabilidade, os ambientes rurais que usam dessa metodologia são favorecidos pela prática econômica, socioambiental e desfrutam de tecnologias inovadoras que potencializam um futuro sustentável.

De um modo geral, o planejamento e a gestão territorial são ferramentas administrativas que caracterizam a realidade atual e, por conseguinte, avaliam condições para um referencial futuro, garantindo a organização do uso e ocupação do território. Por isso, para planejar e organizar um território rural deve-se antes conhecer a realidade e a particularidade deste espaço (MESQUITA; FERREIRA, 2016).

O grande instrumento viabilizador da proposta de planejamento é o desenvolvimento das técnicas de geração e análise de informação espacial, ou seja, as técnicas de geoprocessamento (FARINA, 2006, p. 02). Observa-se hoje no Brasil o uso do geoprocessamento como um instrumento viabilizador de apoio a tomada de decisões a diversos meios relacionados ao planejamento do território rural. Por meio de dados provenientes com o auxílio do sensoriamento remoto em um sistema de informação geográfica (SIG), é possível detectar, prevenir problemas ambientais bem como garantir a sustentabilidade no espaço rural.

Segundo Santos (2012) esse instrumento auxilia, portanto, no processamento preliminar de análise de dados técnicos que são possíveis de serem interpretados pela sociedade. O SIG permite estabelecer, gerenciar e manipular dados em ambiente computacional geridas por atributos temporais, espaciais e temáticos.

A aquisição desses dados é representada por atributos espaciais da superfície da Terra que são importantes instrumentos quando se referem ao gerenciamento de sociedades organizadas, bem como o uso sustentável de territórios. Ou seja, o geoprocessamento auxilia nas técnicas de sustentabilidade 
simulando as consequências que podem vir a acontecer no crescimento e transformação de determinada área.

O setor agrícola no Brasil é diversificado e representa um dos principais motores econômicos do país. No século XXI a agricultura intensiva trouxe o contínuo avanço de tecnologias no espaço rural, viabilizando uma série de inovações para o sistema da agroindústria. Dentre a grande variedade de culturas agrícolas destaca-se a rizicultura, sendo uma importante fonte de concentração latifundiária no sul do Brasil. A produção de arroz no estado de Santa Catarina afeta consideravelmente na economia do estado, representando cerca de $4 \%$ do PIB da região, concentrada principalmente no litoral (SOSBAI, 2012). A rizicultura vem aliando inovações tecnológicas com formas de sensibilização e preocupação ambiental.

Desde a Conferência do Rio-92 até nos dias atuais com o Programa da Agenda 21, o termo sustentabilidade se tornou um aliado para estas atividades agrícolas.

$\mathrm{O}$ uso do geoprocessamento em atividades rurais aproxima o agricultor na adaptação e no aperfeiçoamento de tecnologias no campo. No planejamento e estudo do espaço agrícola, o uso dos SIGs tem-se mostrado como importante mecanismo ajudando de forma prática, rápida e menos onerosa a estruturação de bancos de dados alfanuméricos e documentos cartográficos com informações que servirão de base para o adequado planejamento de cultivos irrigados (LADWIG et al, 2017).

Nesse sentido, a competitividade e conflitos históricos espaciais nas áreas de rizicultura podem ser solucionadas por meio do uso de softwares de geoprocessamento. Não só isso como esses programas computacionais podem também auxiliar no aumento da produtividade da cultura do arroz e na redução de gastos com insumos agrícolas. Essa ferramenta, portanto, possibilita um melhor gerenciamento da produção agrícola.

No estado de Santa Catarina pesquisas e ações coletivas são fomentadas como um processo de coprodução entre representantes da sociedade civil e trabalhadores rurais, na tentativa de responder aos desafios do desenvolvimento rural regional. Esse caso cabe à Associação de Drenagem e Irrigação Santo Isidoro (ADISI), fundada em 1984 com o objetivo de gerenciar para cada associado o abastecimento de água para irrigação nas lavouras de arroz. Localizada em Nova Veneza e Forquilhinha no sul do estado de Santa Catarina, a ADISI demonstra trabalho de cooperativismo com seus associados.

Diante disso, o objetivo do artigo consiste em analisar resultados de uma base de dados econômicos, sociais e ambientais estruturados em ambiente de SIG que possam auxiliar no planejamento e na gestão territorial da área que compreende os associados da ADISI, considerando 
as problemáticas de competitividade e os gastos com insumos no cultivo do arroz, incorporando neste contexto os atributos relacionados a sustentabilidade.

\section{MATERIAL E MÉTODOS}

Localização e descrição da área de estudo

A área de estudo onde foi realizado o projeto de extensão está inserida na região sul do estado de Santa Catarina, localizada nos municípios de Nova Veneza e Forquilhinha, entre as coordenadas geográficas de Longitudes 49³3'05,42”O e 49³1'59,18”O e Latitudes 28³9'52,42”S e $28^{\circ} 41^{\prime} 48,08^{\prime}$ 'S, (Figura 1) e possui uma extensão territorial aproximada de 5000 ha.

A Associação Drenagem e Irrigação Santo Isidoro (ADISI) fundada no dia 09 de novembro de 1984 tem sua sede no município de Nova Veneza. Possui como missão disciplinar, manter e regular para cada associado à distribuição de água canalizada pelos valos de propriedade imediata desta sociedade.

O total de associados pertencentes a ADISI é de 340 produtores agrícolas, abrangendo os bairros de São Bento Alto, Rio Cedro Médio, São Bento Baixo, Linha 14 de Julho, Linha de Mattia, Linha Reta, Vila Santo Antônio e Vila Santa Catarina, no município de Nova Veneza, e Sanga do Café, Morro Comprido e Santa Rosa, no município de Forquilhinha.

Entre as atividades agrícolas nas propriedades dos associados, a predominante é o cultivo de arroz. Com o relevo plano, a distribuição da água para a irrigação ocorre por meio do método de gravidade, com influência da declividade e da vazão máxima. A água distribuída pela associação é captada no rio São Bento, mediante acordo formalizado junto à CASAN (Companhia Catarinense de Águas e Saneamento). A responsabilidade da Associação sobre a gestão da água começa a partir da barragem situada no leito do rio São Bento na comunidade de São Bento Alto.

\section{Metodologia}

A etapas consistiram em uma revisão bibliográfica, a construção de um banco de dados e um sistema de informação geográfica (SIG). A coleta de dados foi realizada com a aplicação de um questionário em campo. O questionário é composto de 11 blocos de informações conforme segue: a localização, relatos socioeconômicos, culturas anuais, culturas perenes, fruticultura, horticultura, descritores da pecuária, e quais os principais problemas que limitam a produção agrícola e as necessidades para viabilizar a propriedade e a família, insumos agrícolas e avaliação do impacto ecológico. 
Figura 1 - Mapa de localização da área de estudo
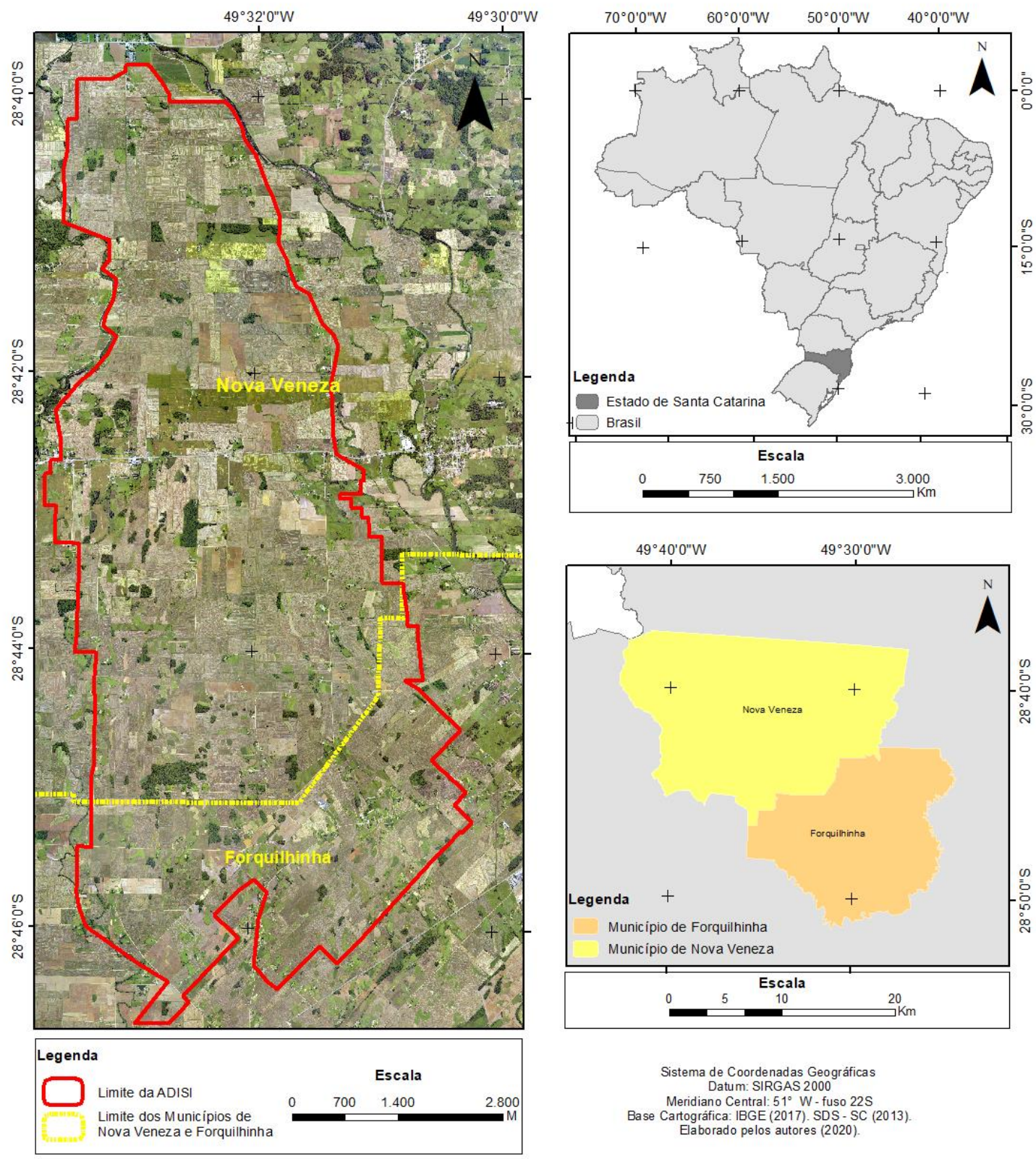

Fonte: Elaboração autores

A digitalização dos dados coletados em campo foi realizada no software Microsoft ACCESS para então trabalhar no ambiente de SIG. O banco de dados é constituído por 18 tabelas, cada tabela possui uma quantidade diferente de linhas de registros, resultando no total de 2692 registros. Cada linha de registro é constituída por colunas de informação.

\section{DISCUSSÃO DOS RESULTADOS}

\section{A inserção do programa Provárzeas nas propriedades associadas na ADISI}


A agricultura no sul do Estado de Santa Catarina até a década de 1970 era em sua grande parte operada manualmente. Antes da mecanização inserida na cultura do arroz, o solo era preparado com grande intensificação de trabalho humano, ocasionando baixa produtividade e certa instabilidade de lucro final. Esse período ficou marcado pela forte crise econômica.

Somente a partir da década de 1970, esse processo começou a mudar com a intensificação da modernização tecnológica na produção rizícola (SILVA, 2003). Nesse período, o cultivo do arroz em Santa Catarina passou por grandes mudanças, como a introdução de maquinários modernos, políticas de crédito e subsídios e, principalmente, a troca do trabalho manual pelo mecanizado (MINATTO; CORRÊA, 2003). Essas transformações começaram a se intensificar mais acentuadamente após a década de 1980, com a implantação do Provárzeas, que era implementado até então no estado de Minas Gerais.

O Programa de Aproveitamento Racional das Várzeas Irrigáveis (PROVÁRZEAS), foi oficializado através do Decreto n. 86. 146 de 23 de junho de 1981. A inserção da modernização aos pequenos agricultores era um dos objetivos centrais deste programa, como se pode observar no Decreto:

Art. $1^{\circ}$ - É criado o Programa Nacional para Aproveitamento de Várzeas Irrigáveis - PROVÁRZEAS NACIONAL, com a finalidade de promover o aproveitamento racional e gradativo de áreas de várzeas nacionais a nível de propriedade rural.

$\S 1^{\circ}$ - Serão beneficiários do PROVÁRZEAS NACIONAL os produtores rurais e suas cooperativas, através de financiamento e suporte técnicoadministrativo na drenagem e sistematização de suas várzeas, dando-se prioridade ao atendimento dos mini e pequenos produtores localizados, preferencialmente, em áreas com infraestrutura básica já implantada.

$\S 2^{\circ}$ - O PROVÁRZEAS NACIONAL será desenvolvido em consonância com outros programas e projetos de apoio ao desenvolvimento rural e suas atividades se estenderão por todo o Território Nacional.

Esse programa possibilitou o aumento significativo da produção de arroz, antes sem representatividade, tornando as áreas de rizicultura do sul do estado de Santa Catarina altamente modernizados, a partir da adoção de novas técnicas e manejos, como foi o sistema de arroz prégerminado. Em âmbito nacional, o programa resultou em um crescimento da área irrigada de quase $70 \%$ durante os anos 1980 em relação à década de 1970 (PROVÁRZEAS, 1986). 
Em 1982, o município de Nova Veneza recebeu equipes especializados para implementação do programa Provárzeas. A região passou a obter lucros substanciais: a quantidade de sacos de arroz aumentou em média de 80 para mais de 130 sacos por hectare (PRESA, 2011).

Nos municípios de Nova Veneza e Forquilhinha, incorporados pela Associação de Drenagem e Irrigação de Santo Izidoro (ADISI), o programa Provárzeas obteve grande adaptação e êxito em sua implantação, pois a região possui um relevo plano e alagado e com clima favorável para a atuação do cultivo da cultura irrigada, aumentando enormemente a área plantada e a produtividade.

Atualmente, o programa é representado pela intensificação tecnológica no campo, resultando em fatores como alta produtividade e diminuição de trabalho humano. No entanto, restringe-se ao fato de que esse processo gerou certa dependência de tecnologias e degradação ambiental.

\section{Cultivo e produção}

Atualmente a ADISI conta com 237 agricultores associados numa área total de aproximadamente 5000 hectares, sendo 2850 hectares destinados ao cultivo do arroz irrigado.

A tabela 1 aponta os valores de área cultivada em hectares nos meses destinados ao plantio nos períodos históricos da cultura do arroz irrigado das safras de 2000 até 2020.

Tabela 1 - Distribuição da área cultivada em hectares nos meses de plantio

\begin{tabular}{cccccc}
\hline Safras & \multicolumn{5}{c}{ Meses de Plantio } \\
\hline Ano/Mês & Agosto & Setembro & Outubro & Novembro & Total \\
$2000 / 2001$ & 150 & 1000 & 1200 & 150 & 2500 \\
$2001 / 2002$ & 140 & 1200 & 900 & 260 & 2500 \\
$2002 / 2003$ & 130 & 950 & 1300 & 120 & 2500 \\
$2003 / 2004$ & 30 & 70 & 2000 & 400 & 2500 \\
$2004 / 2005$ & 130 & 1500 & 1100 & 70 & 2500 \\
$2005 / 2006$ & 150 & 1080 & 1480 & 90 & 2500 \\
$2006 / 2007$ & 160 & 1050 & 1350 & 240 & 2500 \\
$2007 / 2008$ & 150 & 1100 & 1515 & 35 & 2500 \\
$2008 / 2009$ & 165 & 2000 & 620 & 15 & 2500 \\
$2009 / 2010$ & 150 & 1130 & 1500 & 70 & 2500 \\
$2010 / 2011$ & 170 & 1780 & 735 & 165 & 2500 \\
$2011 / 2012$ & 240 & 1790 & 780 & 40 & 2850 \\
$2012 / 2013$ & 206 & 1665 & 950 & 29 & 2850 \\
$2013 / 2014$ & 560 & 1450 & 840 & 0 & 2850 \\
$2014 / 2015$ & 980 & 1559 & 311 & 0 & 2850 \\
\hline
\end{tabular}




\begin{tabular}{lccccc}
\hline $2015 / 2016$ & 705 & 1455 & 418 & 272 & 2850 \\
$2016 / 2017$ & 293 & 2055 & 402 & 100 & 2850 \\
$2017 / 2018$ & 1315 & 1545 & 140 & 0 & 2850 \\
$2018 / 2019$ & 492 & 1932 & 546 & 30 & 2850 \\
$2019 / 2020$ & 759 & 1826 & 415 & 0 & 2850
\end{tabular}

Fonte: Adaptado de ADISI e EPAGRI (2020).

Na safra 2011/2012, o total das áreas cultivadas no domínio da Associação aumentou cerca de 350 hectares. Tais resultados estão associados devido a ampliação da área de cultivo nas propriedades já existentes.

Segundo a tabela 1, os meses de setembro e outubro ao longo dos anos de 2000 a 2020, concentraram o maior número de hectares plantados. A partir da safra de 2012/2013 houve um decréscimo no número de hectares cultivados no mês de outubro e um acréscimo no mês de agosto. Este fator está diretamente associado ao regime de chuvas, caracterizado pelo baixo índice pluviométrico no mês de agosto a partir do ano de 2015 e um pico máximo de chuva em outubro, do mesmo ano. Abaixo segue a tabela 2 do índice pluviométrico de Nova Veneza nos anos de 2000 a 2019.

Tabela 2 - Média mensal do índice pluviométrico de Nova Veneza (2000-2019)

\begin{tabular}{ccccc}
\hline Ano\Mês & Agosto & Setembro & Outubro & Novembro \\
\hline 2000 & 46,10 & 202,90 & 209,70 & 168,70 \\
2001 & 35,40 & 263,90 & 174,60 & 220,80 \\
2002 & 82,10 & 86,10 & 240,70 & 223,70 \\
2003 & 26,00 & 104,50 & 177,40 & 122,70 \\
2004 & 31,50 & 252,60 & 86,40 & 175,90 \\
2005 & 285,40 & 231,60 & 328,00 & 146,70 \\
2006 & 95,50 & 27,20 & 131,50 & 416,20 \\
2007 & 119,60 & 180,10 & 118,20 & 167,30 \\
2008 & 50,90 & 177,00 & 279,20 & 335,20 \\
2009 & 165,00 & 428,80 & 89,50 & 179,60 \\
2010 & 4,30 & 117,10 & 146,70 & 307,00 \\
2011 & 310,50 & 125,50 & 96,50 & 54,80 \\
2012 & 132,20 & 128,30 & 169,20 & 67,90 \\
2013 & 435,80 & 130,00 & 62,80 & 129,60 \\
\hline
\end{tabular}




\begin{tabular}{ccccc}
\hline 2014 & 108,80 & & & 170,70 \\
2015 & 57,10 & 257,50 & 296,50 & 201,00 \\
2016 & 59,00 & 60,90 & 225,50 & \\
2017 & 110,70 & 58,40 & 155,40 & 163,20 \\
2018 & 86,10 & 251,10 & 242,50 & 143,20 \\
2019 & 46,70 & 73,90 & 214,90 & 202,50 \\
Média mensal & 114,44 & 166,18 & 181,33 & 189,30 \\
\hline
\end{tabular}

Fonte: EPAGRI - SC (2019).

Para os agricultores, o plantio da cultura do arroz se dá em condições de menor pluviosidade, já que em períodos de estiagem a fase de semeadura e o trabalho de maquinários rende mais. Um mês extremamente chuvoso prejudica o preparo do solo e o plantio.

Todas essas relações de clima e plantio são conhecidas pelos agricultores da região, pois o conhecimento dos fatores climáticos é fundamental para não perder as plantações de arroz.

A entrada de novas tecnologias nas formas de plantio do arroz e, os investimentos em mecanização pelo projeto Provárzeas validaram as expectativas dos agricultores quanto ao rendimento anual das safras. Antes da introdução do sistema nas lavouras os agricultores não estavam confiantes e pouco convencidos de que o programa daria resultados satisfatórios.

Antes da introdução das novas tecnologias, o processo de plantio era realizado utilizando semeadeiras em linha que necessitavam de um elevado número de trabalhadores para sua realização. Até 1970, a média de sacos de arroz colhidos por hectare ficava entre 30 a 40 sacos. Essa quantidade era pequena para suprir a qualidade de vida dos produtores rurais e o suprimento dos mercados de Santa Catarina (OLIVEIRA; BIZ; SALVARO, 2016).

Os efeitos das transformações tecnológicas foram imediatos a partir de 1980, porque houve um aumento significativo da produção do arroz, passando a mais de 150 sacas por hectare, como mostra a tabela 3 .

O programa Provárzeas, portanto, têm proporcionado aos produtores maior quantidade e qualidade na produção se comparado há décadas atrás com sistemas de plantio mais rudimentares. Atualmente, considera-se cada vez mais o desejo dos produtores rurais de alcançar níveis competitivos. A tabela 3 exibe a quantidade de sacas de arroz produzidos por hectare cultivado nos períodos históricos da safra de 2007 a 2020, nas propriedades associadas da ADISI. 
Tabela 3 - Produção de sacas por hectare nas safras

\begin{tabular}{ccc}
\hline Safras & $\begin{array}{c}\text { Sacas hectare }- \\
\text { ADISI }\end{array}$ & $\begin{array}{c}\text { Média sacas hectare - } \\
\text { Nova Veneza }\end{array}$ \\
\hline $2007 / 2008$ & 150 & 141,40 \\
$2008 / 2009$ & 153 & 147 \\
$2009 / 2010$ & 146 & 137,40 \\
$2010 / 2011$ & 148 & 132,00 \\
$2011 / 2012$ & 139 & 123,16 \\
$2012 / 2013$ & 166 & 128,90 \\
$2013 / 2014$ & 156 & 143,96 \\
$2014 / 2015$ & 148 & 135,46 \\
$2015 / 2016$ & 158 & 143,64 \\
$2016 / 2017$ & 172 & 164,06 \\
$2017 / 2018$ & 165 & 150,96 \\
$2018 / 2019$ & 152 & 148,42 \\
$2019 / 2020$ & 184,9 & -- \\
\hline
\end{tabular}

Fonte: ADISI e EPAGRI (2020).

Nota-se um sutil acréscimo na quantidade de sacas produzidas por hectare ao longo das safras pelos associados. Na safra de 2019/2020, o número de sacas foi a mais substancial desde 2007. Isso pode evidenciar que, futuramente, os produtores rurais terão ainda mais rendimento de produção por hectare cultivado.

Porém, o que tange os métodos utilizados pelo Provárzeas, o fortalecimento do ganho econômico se dará junto aos produtores que possuem de mais terra agriculturável, recursos para investimentos em mecanização e técnicas de cultivo, afetando negativamente os que dispõem de pouca terra agricultável e com escassez de recursos para investimentos esta realidade prejudicará a distribuição de renda na região.

\section{Dimensão econômica e visão atual do rendimento econômico pelos agricultores}

Em relação aos resultados da pesquisa dos questionários aplicados aos produtores rurais, a maioria se manifestou sobre as dificuldades encontradas na lavoura, principalmente as financeiras. Eles questionaram sobre o baixo preço do arroz no mercado, seguido do elevado preço dos insumos. Segundo eles, não há nada a recorrer, já que, são necessárias fortes doses de adubação e outros insumos agrícolas para ter o produto aceito pelo mercado (CREPALDI, 2012). Por isso, não há outra forma senão comprar anualmente os insumos, mesmo com seu preço em alta. 
O método de aquisição dos insumos agrícolas tomada pelos agricultores evidencia a predominância do individualismo. Os produtores rurais ao responder o questionário, admitem que a compra de defensivos e fertilizantes agrícolas é feita de forma individual, mesmo que, a maioria deles necessitam e adquirem os insumos na mesma época do ano. Uma vez que os agricultores compram os mesmos produtos do mercado no mesmo período, e de forma individualizada, concretiza na indução de consequências econômicas, ou seja, o mercado aumenta o valor sobre os insumos, admitindo que no período pré-safra a demanda é maior.

Nas propriedades dos associados da ADISI, o mês de agosto apresenta uma maior demanda quando comparado aos outros meses no quesito da compra de insumos agrícolas. Isso se dá ao fato de que a época indicada de plantio do arroz irrigado é de 21 de agosto a 30 de novembro. Porém, grande parte dos agricultores constataram que não possuem um mês definido na compra de insumos, ou compram quando há necessidade ou adquirem nos meses anteriores ao plantio do arroz. A Figura 1 exibe a movimentação de insumos adquiridos no ano de 2019 pelos associados da ADISI.

Considerando a discussão anterior e que pode ser confirmada na base de dados do ano de 2019, pode-se afirmar que os resultados apresentam certa fragilidade no desenvolvimento econômico sustentável no território dos associados da ADISI, visto que os agricultores não conseguem balizar o controle de custo de suas atividades, sobretudo na decisão de compra de insumos agrícolas sem análise prévia do seu impacto sobre o custo total de produção, afetando especialmente sua lucratividade.

Figura 1 - Meses de aquisição dos insumos da safra de 2019

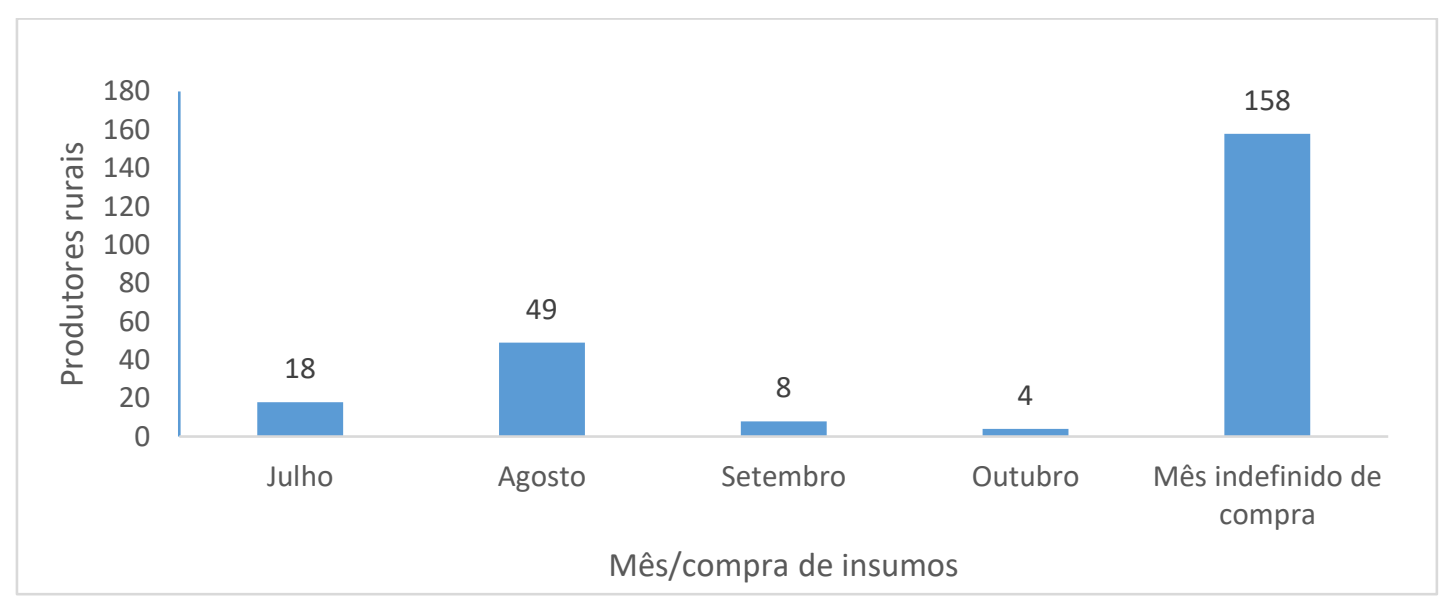

Fonte: Elaborada pelos autores (2020)

Portanto, o associativismo deve ser fomentado no que diz respeito a compra de insumos, que pode ser realizada em conjunto, garantindo melhores condições de negociação na aquisição e entrega destes produtos. 
Por isso, planejar a lavoura sem prognóstico da flutuação do custo dos defensivos agrícolas ou, além disso, utilizar de forma errônea a quantidade certa de dosagens e época de aplicação, diminui a eficiência financeira, acarretando em prejuízos econômicos para a safra de arroz. Esses fatores geram certa dificuldade quanto à competitividade do agronegócio.

Outra condição que poderá causar desequilíbrio econômico no território dos associados da ADISI é a adoção do sistema de cobrança pelo uso da água, regulamentada pela Lei Federal nº 9.433, de 08 de janeiro de 1997. Os sistemas de canais que ligam e abastecem as lavouras de rizicultura serão controlados com o objetivo de reduzir o volume de consumo de água na região, atendendo os princípios da sustentabilidade. Esse método, porém, pode influenciar em um baixo rendimento econômico, refletindo no preço do produto final. Segundo Santos (2002), a cobrança pelo uso da água traz preocupações quanto ao impacto na cadeia produtiva agrícola e, mesmo que o valor cobrado pela água possa ser considerado baixo, o mercado se mostra muito competitivo e qualquer aumento deve ser considerado.

Um estudo realizado por Ladwig et al (2017), demonstra que, com o custo de produção da cultura do arroz elevado, o rendimento econômico se torna baixo. Portanto, a implantação da cobrança pelo uso da água pode afetar ainda mais na produção desta cultura, principalmente quando as áreas são arrendadas.

O processo de modernização e mecanização prioriza objetivar mais lucro na lavoura, e muitas vezes, fatores como condições sociais dos agricultores e a própria questão ambiental ficam de lado. Uma das principais consequências negativas das tecnologias aos trabalhadores rurais foi a sua substituição pelas máquinas, e a eliminação dos produtores com menores áreas de terras. Além disso, a modernização no campo demanda de novos equipamentos e insumos de última geração, aumentando os custos operacionais (EPAGRI, 2012). Por isso, os altos investimentos seguidos de baixo retorno do lucro da produção e principalmente a dependência do clima para não prejudicar a safra são fatores que geram certa instabilidade aos pequenos agricultores.

Dados do Censo Agropecuário de 2006 apontaram diferenças entre grandes e pequenas propriedades rurais do Brasil. Os grandes estabelecimentos somavam apenas 0,91\% do total dos estabelecimentos rurais brasileiros, mas concentravam $45 \%$ de toda a área rural do país. Por outro lado, os estabelecimentos com área inferior a 10 hectares representavam mais de $47 \%$ do total de estabelecimentos do país, mas ocupavam menos de 2,3\% da área total.

Dessa forma, na dimensão econômica pode destacar a instabilidade e a baixa competitividade do sistema aos pequenos agricultores em relação aos que provém de grandes propriedades. Umas das circunstâncias que afetam a competitividade entre agricultores é o armazenamento de grãos em silos privados. $\mathrm{O}$ produtor que investe em armazenagem na própria residência economiza gastos com 
locomoção, conserva o produto disponível no local de produção e detêm da disponibilidade de aguardar para vender grãos durante a entressafra, em momento que os preços estejam mais lucrativos. Em sua grande maioria, os que possuem esse benefício são os proprietários que possuem um maior número de hectares cultivados, segundo dados coletados no questionário.

Para os pequenos produtores rurais, em decorrência do elevado custo de produção e quedas susceptíveis no preço, uma das alternativas para segurança financeira é recorrer de empréstimos bancários de longo prazo. Esse ciclo contínuo afeta significantemente a má adaptação dos pequenos produtores no controle de custos, e, em muitos casos de dívidas altas, a última alternativa é a venda de terras agricultáveis para grandes produtores rurais e empresas da região que, dispõem de benefícios para a concessão de créditos bancários. Por vez, essa contradição leva o capital a se concentrar na mão de poucos, abrindo espaço para a dependência de pequenos produtores rurais aos grandes latifundiários.

Com relação à dimensão econômica, ficou caracterizado a necessidade de aprimorar as interações do sistema com outras atividades socioeconômicas desenvolvidas na região. Segundo Ferreira (2008) o lucro nas mãos de empresas e latifúndios não supre todas as necessidades da região, são as pequenas propriedades que abastecem a economia local. Por isso, para obter o controle do custo da produção e da economia de pequenos agricultores, uma das opções é diversificar a cultura.

Esse sistema quase que abrangente da monocultura do arroz poderá trazer prejuízos a longo prazo, como a maior probabilidade de proliferação de doenças e pragas, e consequentemente, a necessidade de maiores dosagens de defensivos agrícolas (LADWIG et al, 2017). Segundo os respondentes do questionário, há diversas espécies de pragas afetando atualmente a cultura do arroz, dentre elas estão: bicudo, percevejo e caramujo. Essas pragas requerem grandes quantidades de agrotóxicos, aumentando ainda mais os custos finais da produção.

Por isso, a rotação de cultura que seja similar à sistematização do solo nas terras cultivadas do arroz trará benefícios econômicos ao produtor rural. Essa alternativa facilita a obtenção de lucro em diferentes épocas do ano e também colabora no aproveitamento da mesma área de cultivo e dos insumos para a rotação de culturas. A diversificação é uma forma de ganho econômico, oferecendo um certo equilíbrio nos gastos e no lucro total de um pequeno agricultor.

\section{Dimensão ambiental}

A prática da rizicultura exige mudança no uso do solo e outros recursos naturais para o cultivo se consolidar de maneira eficiente. Esses parâmetros geram certos impactos ambientais, não necessariamente de caráter nocivo, apesar de grande parte das vezes serem extremamente prejudiciais para o meio ambiente. No caso da lavoura do arroz, o manejo inadequado da área potencializa os 
riscos eventuais de contaminação dos recursos hídricos, comprometendo a sobrevivência de espécies de seres vivos assim como a própria biodiversidade existente no local.

O programa Provárzeas promoveu uma série de impactos ambientais, podendo-se citar o uso intensivo de agrotóxicos, assim como seu uso indevido, o aumento de maquinários agrícolas em consumo de óleo diesel. Além do desmatamento de grandes áreas para a transformação de várzeas irrigadas (OLIVEIRA; BIZ; SALVARO, 2016). Quanto ao desenvolvimento sustentável, vale salientar que em nome da dimensão econômica a sustentabilidade ambiental é atingida em grande parte desfavoravelmente.

Por isso, provocar impacto econômicos e ambientais, tendem a sofrer consequências negativos de um modo geral, enfraquecendo a sustentabilidade da localidade. Principalmente na produção de alimentos como o arroz, que pressiona substancialmente os ecossistemas naturais. Entretanto, quanto menor o impacto e maior a produtividade do agrossistema, mais sustentável será o modelo agrícola.

Com o objetivo de diminuir os impactos ambientais, alternativas podem ser consideradas pelos agricultores. Uma delas é a adoção da rizipiscicultura, que é a criação de peixes nas lavouras de arroz para a predação de invasores da planta, além da comercialização dos próprios peixes como alternativa de renda extra. Outra alternativa é a soltura de marrecos de Pequim nas várzeas após a época da colheita do arroz. Os animas se alimentam de insetos e plantas que interferem no crescimento do arroz (EPAGRI, 2010).

Dessa forma, a adoção de medidas que beneficiam tanto o produtor quanto o meio ambiente, ou seja, o trabalho em harmonia entre as relações sociais, econômicas e ambientais estarão trabalhando em prol do exercício da sustentabilidade local.

\section{CONSIDERAÇÕES FINAIS}

O Censo Agropecuário realizado pelo IBGE publicado em 2017 aponta os municípios de Forquilhinha e Nova Veneza com maior e quarto maior produtor de arroz com casca no estado de Santa Catarina. O território da ADISI está inserido nos domínios político administrativos destes dois municípios que deixa evidenciado sua importância econômica na arrecadação de tributos.

A base de dados que ficará disponível servirá como referência para a definição de novos projetos e auxiliará na administração de atividades que podem tornar as propriedades mais competitivas no cenário agrícola.

A questão discutida e que ficou evidenciada nos resultados é buscar o equilíbrio no desenvolvimento econômico, social e ecológico considerando o cenário regional, pois os recursos naturais ainda disponíveis precisam ser preservados e conservados para tanto técnicas e tecnologia 
deverão priorizar a geração de novos produtos e inclusive organizar as ações humanas nos processos produtivos incluindo tecnologias de relações de trabalho.

Para concluir, os dados apontam que é necessário que os produtores entendam que as técnicas produtivas e a organização da produção são produtos sociais, consequências de decisões humanas e assim deixar de lado o egoísmo e fomentar o associativismo.

\section{REFERÊNCIAS}

BECKER, Bertha Koifmann. A Geografia e o Resgate da Geopolítica. Espaço Aberto, [S.L.], v. 2, n. 1, p. 117-150, 5 jul. 2012. Revista Espaco Aberto. Disponível em: <http://dx.doi.org/10.36403/espacoaberto.2012.2079>. Acesso em: 05 jul. 2020.

BRASIL. Decreto $\mathbf{n}^{\circ}$ 86.146 de 23.06.81. Dispõe sobre a criação do Programa Nacional para Aproveitamento de Várzeas Irrigáveis - PROVÁRZEAS NACIONAL. Disponível em: <https://www2.camara.leg.br/legin/fed/decret/1980-1987/decreto-86146-23-junho-1981-435419publicacaooriginal-1-pe.html>. Acesso em: 02 jul. 2020.

CORDEIRO, Antônio Carlos; SUHRE, Elias; MEDEIROS, Roberto Dantas \& VILARINHO, Aloisio Alcantara. Sistemas de cultivo e manejo de água na produção de diferentes genótipos de arroz em várzea, no estado de Roraima. Pesquisa Agropecuária Tropical, 40(3), 362-369. 2010.

CORRÊA, Roberto Lobato. Algumas reflexões sobre a gestão do território. Rio de Janeiro: UFRJ/Departamento de Geografia/LAGET, 1987. Disponível em: <http://observatoriogeograficoamericalatina.org.mx/egal2/Geografiasoc ioeconomica/Ordenamientoterritorial/03.pdf>. Acesso em: 02 jul. 2020. CORRÊA, Roberto Lobato. Corporação, Práticas Espaciais e Gestão do Território. Revista Brasileira de Geografia, 54(3), 1992.

CREPALDI, Silvio Aparecido. Contabilidade Rural: Uma Abordagem Decisorial. $7^{0}$ edição. São Paulo: Ed. Atlas, 2012.

DALLABRIDA, Valdir Roque. Geograficamente falando, a Governança Territorial como o processo de governo dos territórios. In: II Seminário Internacional SETED-ANTE, Santiago de Compostela, $1^{\circ}$ a 3 de julho de $2015 b$.

EPAGRI. Empresa de Pesquisa Agropecuária e Extensão Rural de Santa Catarina. Arroz irrigado: recomendações técnicas da pesquisa para o sul do Brasil. Santa Catarina: EPAGRI. 2010.

EPAGRI. Empresa de Pesquisa Agropecuária e Extensão Rural de Santa Catarina. Arroz irrigado: recomendações técnicas da pesquisa para o Sul do Brasil. Santa Catarina: EPAGRI. 2012.

FARINA, Flávia. Abordagem sobre as técnicas de geoprocessamento aplicadas ao planejamento e gestão urbana. Cad. EBAPE.BR, Dez 2006, vol.4, no.4, p.01-13. ISSN 1679-3951.

FERREIRA, Carlos Magri. SUSTENTABILIDADE DE SISTEMAS DE PRODUÇÃO DE ARROZ DE TERRAS ALTAS. Informações Econômicas, São Paulo, v. 38, n. 11, p. 59-70, nov. 2008.

IBGE. Instituto Brasileiro de Geografia e Estatística. Censo Agropecuário de 2006. Rio de Janeiro, IBGE, $2009 . \quad$ Disponível em: <https://biblioteca.ibge.gov.br/visualizacao/periodicos/51/agro_2006.pdf>. Acesso em: 19 mai. 2020.

IBGE. Instituto Brasileiro de Geografia e Estatística. Censo Agropecuário de 2017. Disponível:<https://censos.ibge.gov.br/agro/2017/templates/censo_agro/resultadosagro/agricultura. html?localidade $=42 \&$ tema $=76424>$ Acesso em: 11/08/2020.

LADWIG, Nilzo Ivo; SILVA, SILVA, Eulinor Pereira da; BACK, Álvaro José. A cobrança do uso da água e o impacto no custo da produção do arroz irrigado na região Sul do Estado de Santa Catarina. Boletim de Geografia, [S.L.], v. 35, n. 2, p. 31, 1 dez. 2017. Universidade Estadual de Maringá. Disponível em: <http://dx.doi.org/10.4025/bolgeogr.v35i2.31711>. Acesso em: 10 jul. 2020. 
LOCH, Ruth Emilia Nogueira. Cartografia: representação, comunicação e visualização de dados espaciais. Florianópolis: Ed. UFSC, 2006. 314 p. ISBN 853280344X.

MESQUITA, Amanda Pires de; FERREIRA, William Rodrigues. O município e o planejamento do território rural no Brasil. Revista Geográfica de América Central, Universidad Nacional, Costa Rica, v. 1, n. 58, p. 1-15, mai. 2016.

MINATTO, João Marcos; CORRÊA, Walquíria Krugger. As Estratégias de reprodução na agricultura familiar em Turvo (SC). Geosul, 18(36), 77- 98. 2003.

OLIVEIRA, Estevam Dimas de; BIZ, Jádna Bilésimo; SALVARO, Giovana Ilka Jacinto. A trajetória de modernização da cultura do arroz no município de Turvo - Santa Catarina, brasil. Revista Agroalimentaria, Universidad de los Andes, v. 22, n. 43, p. 1-14, 3 jul. 2016.

ORTEGA, Antonio César. Desenvolvimento territorial rural no Brasil: limites e potencialidades dos consads. Revista de Economia e Sociologia Rural, [S.L.], v. 45, n. 2, p. 275-300, jun. 2007. FapUNIFESP (SciELO). Disponível em: <http://dx.doi.org/10.1590/s0103-20032007000200003>. Acesso em: 4 jul. 2020.

PRESA, Juliana Brocca. "O arroz no espigão e o milho no banhado": Programa PROVÁRZEAS - o desenvolvimento de uma política pública e o cultivo de arroz em municípios da Bacia do Rio Araranguá. 195p. Dissertação (Mestrado) - Universidade Federal de Santa Catarina, Centro de Filosofia de Ciências Humanas, Programa de Pós-Graduação em História, Florianópolis, 2011.

PROGRAMA NACIONAL DE IRRIGACAO (Brasil). Profir, Provárzea. Brasília, 1986. 34p. PTDRS SERRA CATARINENSE. Plano Territorial de Desenvolvimento Rural Sustentável do Território da Serra Catarinense. Lages: Codeter, 2011.

REYNAUD, Jean-Daniel. Préface. In: REYNAUD, Jean-Daniel. Les règles du jeu. L'action collective et la regulation sociale. Paris: Armand Colin, 2004. p. XII-XIX.

SANTOS, Celiane Silva. Os sistemas de informação geográfica aplicados à análise espacial para o mapeamento dos espaços verdes do bairro do Cabula na cidade do Salvador - Bahia - Brasil. 2012. 117 f. Dissertação (Mestrado) - Curso de Mestrado em Gestão do Território, Universidade Nova de Lisboa, Salvador, 2012.

SANTOS, Marilene de Oliveira Ramos Múmias dos. O Impacto da Cobrança pelo Uso da Água no Comportamento do Usuário. COPPE/UFRJ, D.Sc., Engenharia Civil, Tese - Universidade Federal do Rio de Janeiro, COPPE, Rio de Janeiro-RJ 2002.

SILVA, José Graziano da. Tecnologia e agricultura familiar. $2^{\mathrm{a}}$ Ed. Rio Grande do Sul: UFRGS Editora. 2003.

SOSBAI. Reunião Técnica da Cultura do Arroz Irrigado: Recomendações técnicas da pesquisa para o Sul do Brasil. Sociedade Sul-Brasileira de Arroz Irrigado. Itajaí, SC: SOSBAI, 2012.179p.CERR. 